\title{
SYNOVECTOMY OF THE ELBOW AND RADIAL HEAD EXCISION IN RHEUMATOID ARTHRITIS
}

\author{
PREDICTIVE FACTORS AND LONG-TERM OUTCOME
}

NAGUI S. T. GENDI, JEREMY M. C. AXON, ANDREW J. CARR, KEVIN D. PILE, PETER D. BURGE, ALASTAIR G. MOWAT

From the Nuffield Orthopaedic Centre, Oxford, England

We carried out a survival analysis of elbow synovectomy (ES) and excision of the radial head (RHE) performed on 171 rheumatoid elbows. The failure criteria were revision surgery (performed or desired) and/or the presence of significant or severe pain.

The cumulative survival was $81 \%$ at one year which thereafter decreased by an average of $2.6 \%$ per year. The strongest predictor for success was a low preoperative range of supination-pronation when corresponding survival curves were compared. A low range of flexion-extension also predicted failure. Combining both factors gave better prediction (failure: $6.3 \% \vee 67 \%$ ), but a long duration of elbow symptoms before surgery predicted failure $(72 \%, p=0.04)$.

At review, there was a mean gain of $50^{\circ}$ in supination-pronation and $11^{\circ}$ in flexion-extension; both correlated with success. Failure correlated with recurrence of synovitis, elbow instability, ulnar neuropathy, poor general mobility and poor upper-limb function. The last was independently affected by the severity of RA in the ipsilateral shoulder.

Our findings show that although the short-term result of ES and RHE in rheumatoid arthritis is good, the long-term outcome is poor except in a subgroup with more than $50 \%$ limitation of forearm rotation.

J Bone Joint Surg [Br] 1997;79-B:918-23.

Received 13 November 1996; Accepted after revision 28 April 1997

N. S. T. Gendi, MSc, MRCP, Consultant Rheumatologist

Basildon Hospital, Nether Mayne, Basildon, Essex SS16 5NL, UK.

J. M. C. Axon, MRCP, Consultant Rheumatologist

Queen Elizabeth II Hospital, Welwyn Garden City, Hertfordshire AL7 4HQ, UK.

K. D. Pile, FRACP, Director

Department of Rheumatology, The Queen Elizabeth Hospital, Adelaide 5011, Australia.

A. G. Mowat, FRCP, FRCP Ed, Consultant Rheumatologist

A. J. Carr, FRCS Consultant Orthopaedic Surgeon

P. D. Burge, FRCS, Consultant Orthopaedic Surgeon

The Nuffield Orthopaedic Centre, Windmill Road, Headington, Oxford OX3 7LD, UK.

Correspondence should be sent to Dr N. S. T. Gendi.

(C)1997 British Editorial Society of Bone and Joint Surgery

0301-620X/97/67408 \$2.00

918
Loads of up to three times the body-weight are often borne by the elbow, ${ }^{1}$ which is involved in over $70 \%$ of patients with established rheumatoid arthritis (RA). ${ }^{2}$ Involvement is usually bilateral and more marked on the dominant side. Many daily activities become restricted by pain, weakness, stiffness and instability. The surgical options are elbow synovectomy (ES), usually combined with radial head excision (RHE), and total elbow replacement (TER). Pain relief of $80 \%$ to $90 \%$ has been claimed with $\mathrm{ES}^{3-5}$ but later studies have shown less satisfactory results and a pattern of gradual deterioration. ${ }^{6,7}$ TER gives excellent relief of pain but the incidence of complications remains around $20 \%$ and the management of infection and loosening is costly. ${ }^{8}$

Our study aimed to redefine the role of ES in RA with regard to predictive factors and outcome in a large group of patients over a 20 -year period.

\section{PATIENTS AND METHODS}

We identified patients from the operation register of the Nuffield Orthopaedic Centre, Oxford, UK. Between June 1972 and May 1991, 230 elbow synovectomies had been performed of which 181 were for RA. Patients who satisfied the 1987 ARA criteria, ${ }^{9}$ and who were cared for by rheumatologists and the upper-limb orthopaedic surgeons, were included (171 elbows). Of these, 46 were in patients who died and ten had been lost to follow-up. The outcome was not determined for these 56 elbows, but the time of surgery and last follow-up was used for survival analysis.

We reviewed 95 patients (115 elbows); 93 elbows were in females. Rheumatoid factor was positive in $68 \%$ of cases. At surgery, the mean age was $55 \pm 13.3$ SD (27 to 85$)$ and the mean duration of rheumatoid arthritis was $15 \pm 8$ years (2 to 35). ES was combined with RHE in all but two patients and with transposition or decompression of the ulnar nerve in ten. Seventy (61\%) operations were on the right elbow.

The patients' notes were reviewed. The duration of symptoms before surgery, the preoperative ranges of movements and operation notes were recorded. Patients who did not have repeat surgery had an interview and examination except for seven (ten elbows) who were unable to attend 
Table I. Survival analysis of elbow synovectomy in rheumatoid arthritis in 171 elbows

\begin{tabular}{|c|c|c|c|c|c|c|c|c|c|}
\hline \multirow{2}{*}{$\begin{array}{l}\text { Interval since } \\
\text { operation } \\
\text { (yr) }\end{array}$} & \multirow{2}{*}{$\begin{array}{l}\text { Number at } \\
\text { start }\end{array}$} & \multicolumn{3}{|c|}{ Withdrawals at last review } & \multirow[b]{2}{*}{ Failed } & \multirow[b]{2}{*}{ Number at risk } & \multirow{2}{*}{$\begin{array}{l}\text { Proportion } \\
\text { failing } \\
(\%)\end{array}$} & \multirow{2}{*}{$\begin{array}{l}\text { Cumulative } \\
\text { survival } \\
(\%)\end{array}$} & \multirow{2}{*}{$\begin{array}{l}\text { Standard } \\
\text { error }\end{array}$} \\
\hline & & Success & Lost & Died & & & & & \\
\hline 0 to 1 & 171 & 3 & 1 & 9 & 32 & 164.5 & 19 & 81 & 3.2 \\
\hline$>1$ to 2 & 126 & 4 & 1 & 2 & 6 & 122.5 & 5 & 77 & 3.5 \\
\hline$>2$ to 3 & 113 & 9 & 0 & 3 & 2 & 107 & 2 & 75 & 3.7 \\
\hline$>3$ to 4 & 99 & 4 & 3 & 3 & 2 & 94 & 2 & 74 & 4.1 \\
\hline$>4$ to 5 & 87 & 6 & 0 & 4 & 0 & 82 & 0 & 74 & 4.3 \\
\hline$>5$ to 6 & 77 & 7 & 0 & 6 & 0 & 70.5 & 0 & 74 & 4.7 \\
\hline$>6$ to 7 & 64 & 2 & 0 & 2 & 1 & 62 & 2 & 72 & 5 \\
\hline$>7$ to 8 & 59 & 9 & 1 & 1 & 0 & 53.5 & 0 & 72 & 5.5 \\
\hline$>8$ to 9 & 48 & 2 & 0 & 2 & 2 & 46 & 4 & 69 & 5.9 \\
\hline$>9$ to 10 & 42 & 4 & 1 & 1 & 2 & 39 & 5 & 66 & 6.6 \\
\hline$>10$ to 11 & 34 & 2 & 1 & 4 & 1 & 30.5 & 3 & 64 & 7.5 \\
\hline$>11$ to 12 & 26 & 3 & 0 & 5 & 3 & 22 & 14 & 55 & 9.5 \\
\hline$>12$ to 13 & 15 & 2 & 0 & 0 & 0 & 14 & 0 & 55 & 10.2 \\
\hline$>13$ to 14 & 13 & 1 & 0 & 2 & 0 & 11.5 & 0 & 55 & 11.7 \\
\hline$>14$ to 15 & 10 & 0 & 1 & 0 & 0 & 9.5 & 0 & 55 & 12.3 \\
\hline$>15$ to 16 & 9 & 1 & 1 & 1 & 1 & 7.5 & 13 & 48 & 15.4 \\
\hline$>16$ to 17 & 5 & 1 & 0 & 0 & 0 & 4.5 & 0 & 48 & 17.2 \\
\hline$>17$ to 18 & 4 & 1 & 0 & 1 & 1 & 3 & 33 & 32 & 26.2 \\
\hline$>18$ to 19 & 1 & 0 & 0 & 0 & 0 & 1 & 0 & 32 & 26.2 \\
\hline$>19$ to 20 & 1 & 1 & 0 & 0 & 0 & 0.5 & 0 & 32 & \\
\hline
\end{tabular}

and who were assessed by a postal questionnaire. Elbow pain was graded by the patient as none, mild, significant or severe. The presence of synovitis, instability in anteroposterior and lateral planes and ulnar neuropathy with paraesthesiae and/or hypoaesthesia in the ring and little fingers was noted. Flexion-extension and supination-pronation were measured in the sitting position, using a standard goniometer for the former and estimation by eye for the latter. ${ }^{10}$ The function of the operated limb was assessed by asking the patients to reach the mouth, touch the back of the head and state whether they could turn a door handle. RA in the other joints (shoulders, wrists and hands and the contralateral elbow) was graded as none/mild, moderate or severe. The degree of mobility and the use of walking aids were recorded. Mobility was considered poor when the patient used a wheelchair and/or was housebound. Information from the questionnaire included the presence and severity of elbow pain and symptoms of ulnar neuropathy, the ability to perform the three upper-limb functions as described above, the degree of mobility and whether further elbow surgery had been performed or desired. Preoperative and up-to-date elbow radiographs were graded using the Larsen-Dale scale ${ }^{11}$ and checked for inter- and intraobserver reliability. The humeroulnar and radiohumeral joints were graded separately. Large cysts and subluxation of the radial head were noted.

Failure was recorded if revision surgery had been performed (TER or ES, but not ulnar nerve transposition or decompression) or desired by the patient or when significant or severe pain was present at review. To determine the time of failure, the patients were asked how long the benefit had lasted, but the recorded clinical notes were also taken into consideration.
Statistical analysis. We performed survival analysis using the actuarial method. ${ }^{12}$ Student's $t$-test (two-sided) for continuous variables and the chi-squared test for categorical variables were used to analyse the difference between the success and failure groups. The ranges of movement were analysed as categories, the limits of which were taken when the relation to outcome was most significant. The relative risk and $95 \%$ confidence intervals $(\mathrm{CI})^{13}$ were determined for factors with predictive value. The Mantel-Haenzel chisquared test was used to allow for confounding. We performed survival analysis separately for the two groups with preoperative supination-pronation ranges of $\leq 80^{\circ}$ and $>80^{\circ}$, and flexion extension ranges of $\leq 60^{\circ}$ and $>60^{\circ}$; the log-rank test was used to determine the statistical significance of the difference. ${ }^{12}$ Student's $t$-test for paired values was used for the change in the range of movements and the Wilcoxon signed-rank test for the change in the radiological grades.

\section{RESULTS}

Outcome. Table I and Figure 1 show the survival analysis. Failure during the first year was 19\%. After the first year the cumulative survival declined gradually by an average of $2.6 \%$ per year. The overall failure rate was $46 \%$ during an average follow-up period of 6.5 years. Failure was declared to be due to significant or severe pain in 17 elbows, the desire to have further surgery in six, to both of these in 21 and to revision surgery in nine (eight TERs and one repeat ES). Five patients required ulnar nerve transposition or decompression.

There was an improvement in the supination-pronation and flexion-extension ranges with a gain of $50^{\circ}$ $(\mathrm{p}=0.0001,95 \% \mathrm{CI} 40$ to 61$)$ and $11^{\circ}(\mathrm{p}=0.001,95 \% \mathrm{CI}$ 


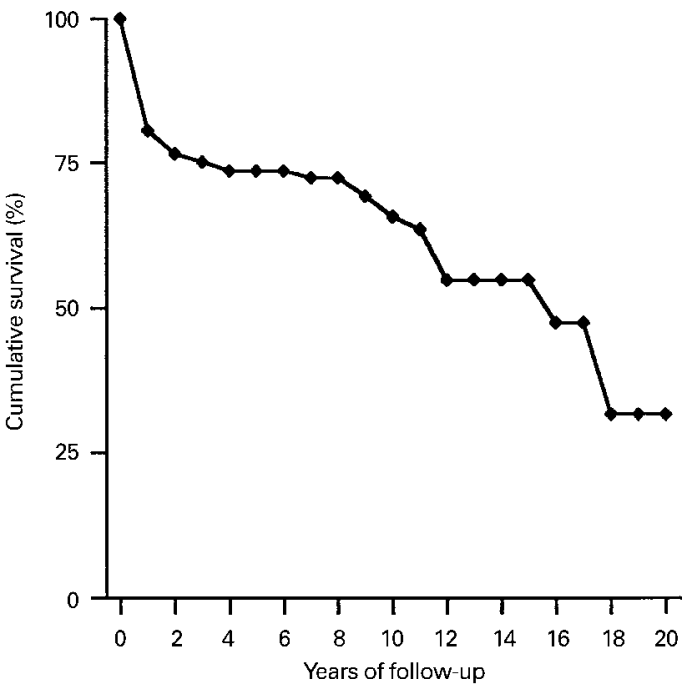

Fig. 1

Survival analysis of elbow synovectomy and radial head excision in rheumatoid arthritis.

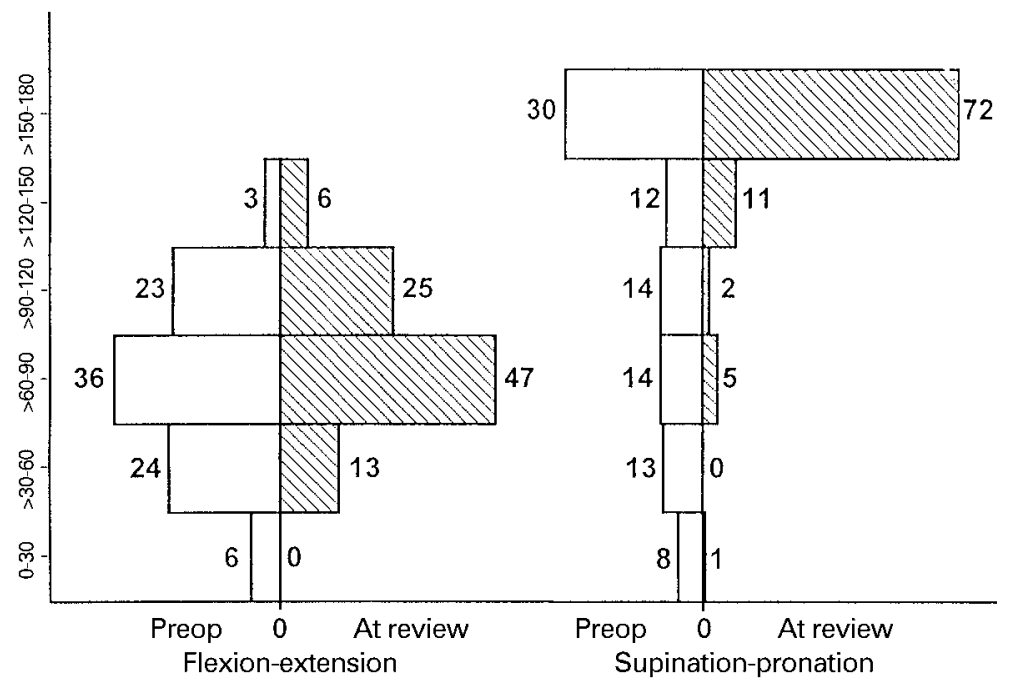

Fig. 2

The frequency distribution of the ranges of supination-pronation and flexion-extension preoperatively and at review.
4 to 17), respectively, compared with preoperative levels. Figure 2 shows the frequency distribution of ranges of movement preoperatively and at review. Synovitis was present in 43\% (42 of 97) and ulnar neuropathy in 19\% (20 of 106). Instability in one plane was present in $18 \%$ (17 of 96 ), and in two planes in a further $18 \%$ (17 of 96).

There was significant radiological progression at the humeroulnar joint, with an increase of the median from three to four on the Larsen scale $(p=0.00003)$.

Outcome predictors. Table II shows the relation of preoperative predictors to outcome. A supination-pronation range of $\leq 80^{\circ}$ predicted success. Similarly, supination $\leq 40^{\circ}$ was a significant predictor of success. A preoperative flexion-extension range of $\leq 60^{\circ}$ predicted failure. The degree of flexion deformity did not affect outcome. A preoperative range of supination-pronation of $\leq 80^{\circ}$, combined with a range of flexion-extension of $<60^{\circ}$, indicated a success rate of $94 \%$ compared with $33 \%$ when supination-pronation of $>80^{\circ}$ was combined with flexion-extension of $\leq 60^{\circ}$. There was no confounding between the ranges of supinationpronation and flexion-extension. Survival analysis in relation to the preoperative range of supination-pronation is shown in Figure 3; the overall difference, using the logrank test, was significant $(\mathrm{RR}=2.2 ; 95 \% \mathrm{CI}$ interval 1.4 to 3.4). Survival analysis in relation to the range of preoperative flexion-extension is shown in Figure 4; the overall difference using the log-rank test was significant $(\mathrm{RR}=2.1 ; 95 \% \mathrm{CI} 1.2$ to 3.7$)$.

The average duration of elbow symptoms before surgery was significantly longer in those who failed (4.1 $v 2.6$ years, $\mathrm{p}=0.01$ ). Failure occurred in 13 of 18 patients who had had elbow symptoms for more than five years (Table II). Confounding was noted between the duration of symptoms and the range of flexion-extension, but not between the duration of symptoms and the range of supination- pronation. Age, gender, duration of RA, rheumatoid factor seropositivity, the side of surgery and hand dominance did not affect the outcome.

Separate radiological grading of the humeroulnar and radiohumeral joints showed good inter- and intraobserver reliability (interclass correlation coefficients were 0.83 and 0.89 , respectively, for the former and 0.75 and 0.72 for the latter). There was no statistically significant relationship between the radiological grade of either of the two elbow components and outcome. Only four humeroulnar joints were radiologically grade 1 preoperatively; they were all successes. The presence or absence of large $(>5 \mathrm{~mm})$ bone cysts and subluxation of the radial head did not alter the outcome.

Failure and success. Success correlated with a large gain in supination-pronation. A gain of $\geq 100^{\circ}$ was associated with $82 \%$ success $(p=0.03)$ and a gain of $\geq 110^{\circ}$ with $88 \%$ success $(p=0.01)$. In the case of flexion-extension, there was a mean gain of $3^{\circ}$ with failure and $16^{\circ}$ with success. The difference was statistically significant $(p=0.04)$, and a gain of $\geq 10^{\circ}$ of flexion-extension correlated with success (64\% success, $\mathrm{p}=0.03)$.

Table III shows the correlation of the upper-limb function with outcome and the severity of disease in other joints of the upper limb. Failure correlated with the recurrence of synovitis, instability in two planes, ulnar neuropathy and reduced mobility (Table IV). There was no correlation with radiological progression or severity of RA in the other joints of the upper limb.

\section{DISCUSSION}

Short-term studies of ES and RHE have claimed excellent results with $100 \%$ pain relief. ${ }^{3,14}$ Other studies with longer follow-up, however, reported success rates varying between 
Table II. The relationship of predictive factors to outcome of elbow synovectomy and radial head excision

\begin{tabular}{|c|c|c|c|c|c|}
\hline & Number & Failure & Success & $\begin{array}{l}\text { Relative risk of } \\
\text { failure }(95 \% \mathrm{CI})\end{array}$ & p value \\
\hline \multicolumn{6}{|c|}{ Range of movement (degrees) } \\
\hline \multicolumn{6}{|c|}{ Supination-pronation* } \\
\hline$\leq 80$ & 32 & 9 & 23 & $0.53(0.32$ to 0.89$)$ & 0.017 \\
\hline$>80$ & 77 & 41 & 36 & & \\
\hline \multicolumn{6}{|l|}{ Supination* } \\
\hline$\leq 40$ & 38 & 12 & 26 & $0.59(0.37$ to 0.94$)$ & 0.029 \\
\hline$>40$ & 67 & 36 & 31 & & \\
\hline \multicolumn{6}{|l|}{ Pronation $\dagger$} \\
\hline$\leq 40$ & 31 & 11 & 20 & $0.71(0.43$ to 1.16$)$ & \\
\hline$>40$ & 74 & 37 & 37 & & \\
\hline \multicolumn{6}{|c|}{ Flexion-extension* } \\
\hline$\leq 60$ & 33 & 20 & 13 & $1.52(1.004$ to 2.29$)$ & 0.048 \\
\hline$>60$ & 75 & 30 & 45 & & \\
\hline \multicolumn{6}{|c|}{ Fixed flexion deformity $\dagger$} \\
\hline$\leq 30$ & 34 & 15 & 19 & & \\
\hline$>30$ to 60 & 67 & 31 & 36 & & \\
\hline$>60$ & 10 & 5 & 5 & & \\
\hline \multicolumn{6}{|c|}{ Supination-pronation and flexion-extension $\neq$} \\
\hline$\leq 80$ and $>60$ & 16 & 1 & 15 & $0.12(0.03$ to 0.41$)$ & 0.003 \\
\hline$\leq 80$ and $\leq 60$ & 15 & 8 & 7 & & \\
\hline$>80$ and $>60$ & 59 & 29 & 30 & & \\
\hline$>80$ and $\leq 60$ & 18 & 12 & 6 & & \\
\hline \multicolumn{6}{|c|}{ Duration of elbow symptoms $(\mathrm{yr})^{*}$} \\
\hline 1 & 36 & 13 & 23 & & \\
\hline$>1$ to 5 & 54 & 24 & 30 & & \\
\hline$>5$ & 18 & 13 & 5 & $1.76(1.11$ to 2.77$)$ & 0.04 \\
\hline
\end{tabular}

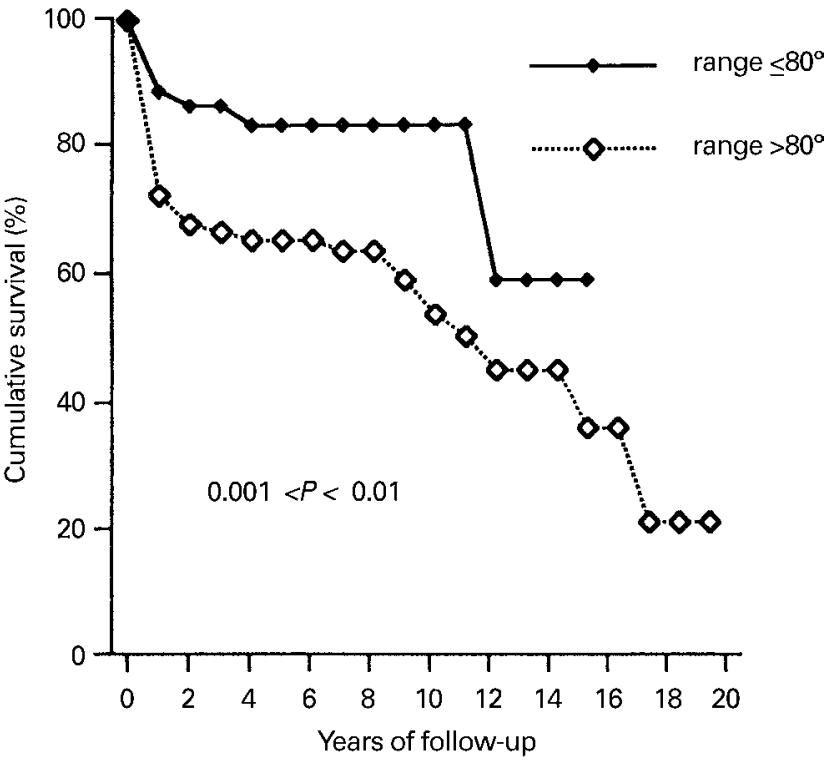

Fig. 3

Survival-analysis curves for elbows classified according to the preoperative range of supination-pronation.

$70 \%$ and $90 \% .^{2,4,5,8,15-19}$ Two recent studies have indicated that initial good results were not maintained. Rymaszewski et al $^{6}$ showed that in 40 elbows the initial pain relief of $70 \%$ was reduced to $45 \%$ at six years and in the study of

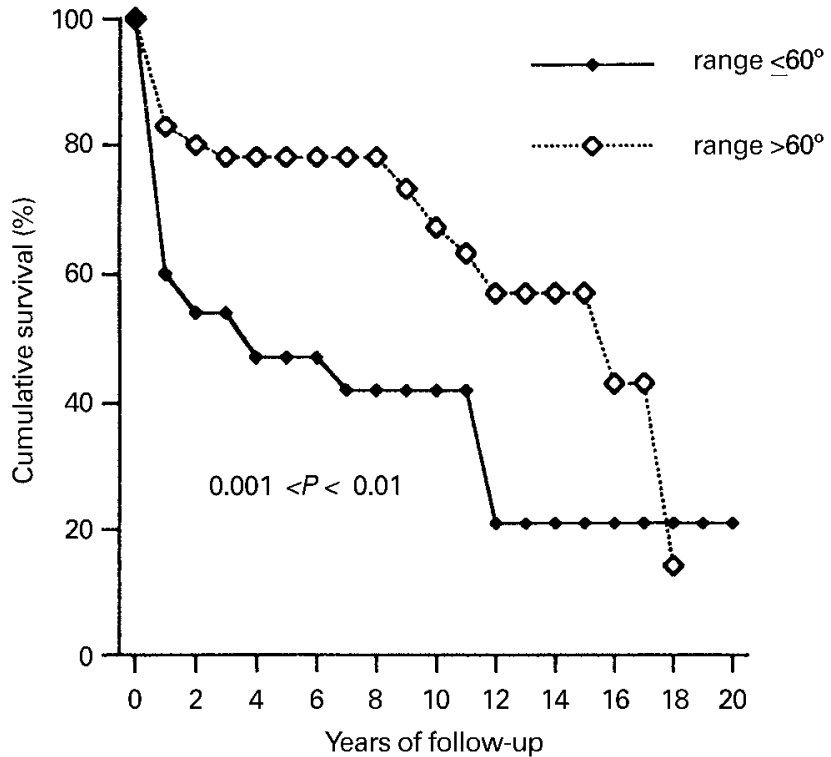

Fig. 4

Survival-analysis curves for elbows classified according to the preoperative range of flexion-extension.

Summers, Taylor and Webley ${ }^{7}$ on 65 elbows $84 \%$ had pain relief at six months, but only $54 \%$ remained painfree at five years. Our findings agree with these results. Survival analysis clarified the pattern of failure; $19 \%$ were primary 
Table III. Association of three measures of upper-limb function with outcome and disease severity in joints of the ipsilateral limb (chi-squared test)

\begin{tabular}{|c|c|c|c|c|c|c|c|c|c|c|c|c|c|c|}
\hline \multirow[b]{3}{*}{ Function } & \multicolumn{14}{|c|}{ Association with } \\
\hline & \multicolumn{4}{|c|}{ Outcome of ES } & \multicolumn{5}{|c|}{ Shoulder disease severity } & \multicolumn{5}{|c|}{ Hand/wrist disease severity } \\
\hline & Total & Failure & Success & $\mathbf{p}$ & Total & Mild & Mod & Severe & $\mathbf{p}$ & Total & Mild & Mod & Severe & $\mathbf{p}$ \\
\hline \multicolumn{15}{|c|}{ Reaching the mouth } \\
\hline Yes & 91 & 33 & 58 & 0.007 & 81 & 48 & 17 & 16 & 0.008 & 81 & 14 & 31 & 36 & 0.2 \\
\hline No & 15 & 11 & 4 & & 14 & 2 & 6 & 6 & & 14 & 0 & 5 & 9 & \\
\hline \multicolumn{15}{|c|}{ Reaching the back of the head } \\
\hline Yes & 61 & 20 & 41 & 0.03 & 54 & 41 & 7 & 6 & 0.0001 & 54 & 12 & 20 & 22 & 0.02 \\
\hline No & 45 & 24 & 21 & & 41 & 9 & 16 & 16 & & 41 & 2 & 16 & 23 & \\
\hline \multicolumn{15}{|c|}{ Turning a door handle } \\
\hline Yes & 77 & 26 & 51 & 0.008 & 70 & 44 & 15 & 11 & 0.002 & 70 & 14 & 28 & 28 & 0.4 \\
\hline No & 29 & 18 & 11 & & 25 & 6 & 8 & 11 & & 25 & 0 & 8 & 17 & \\
\hline
\end{tabular}

Table IV. The association of features at review with the outcome of surgery (chi-squared test)

\begin{tabular}{lllll}
\hline Features at review & Number & Failure & Success & p value \\
\hline $\begin{array}{l}\text { Recurrence of synovitis } \\
\quad \text { Yes }\end{array}$ & 42 & 28 & 14 & \\
$\quad$ No & 55 & 12 & 43 & 0.0001 \\
Ulnar neuropathy & 20 & 13 & 7 & \\
$\quad$ Yes & 86 & 31 & 55 & 0.02 \\
$\quad$ No & 17 & 11 & 6 & \\
Instability* & 79 & 28 & 51 & 0.03 \\
$\quad$ Yes & & & & \\
$\quad$ No & 73 & 25 & 48 & 0.03 \\
Mobility & 32 & 18 & 14 & \\
$\quad$ Good & & & & \\
Poor $\dagger$ & & &
\end{tabular}

* in anteroposterior and lateral planes

$\dagger$ limited to indoors and/or wheelchair

failures within the first year, and the remainder deteriorated gradually over subsequent years.

Since pain is the main indication for elbow surgery, we have used it as an outcome measure. It should not, however, be the sole outcome since it does not always reflect function and may be minimised by a stoical patient. We have therefore included further surgery, whether desired or performed, as a second outcome measure.

Unlike previous studies on ES, we were able to examine the preoperative range of movement as an outcome predictor, since in most of our patients the ranges of movement were routinely recorded with a goniometer, usually in a rheumatology-orthopaedic clinic. Loss of more than half of the normal range of supination-pronation predicted a success rate of more than $70 \%$, while a flexion-extension range of $\leq 60^{\circ}$ predicted a failure rate of $60 \%$. These predictors were independent and improved by combining them to give a success rate approaching $100 \%$ if restricted supinationpronation was accompanied by a range of flexion-extension above $60^{\circ}$. Morrey et al, $^{20}$ in a study on normal elbows, found that most activities of daily living could be accomplished with $100^{\circ}$ of forearm rotation. This, combined with a gain of $50^{\circ}$ in forearm rotation, explains why a low preoperative range of supination-pronation was a predictor of success. Those patients who gained most achieved success. A range of flexion-extension of $100^{\circ}$ is sufficient for most daily activities, most of which are performed between $60^{\circ}$ and $120^{\circ} .^{20}$ Since there was only a modest $10^{\circ}$ gain in flexion-extension, patients with a preoperative range below $60^{\circ}$ failed to benefit. We confirm the finding of Eichenblat, Hass and Kessler ${ }^{21}$ that gain in movement was most evident in forearm rotation and found that supination is more important, perhaps because, unlike pronation, it is not easily augmented by shoulder movement. While $40^{\circ}$ of pronation may be sufficient for most daily activities, at least $60^{\circ}$ of supination are needed for movements such as receiving coins as change. Many activities for self-care are performed with the forearm supinated. ${ }^{20}$ The improvement in the preoperative range of supination-pronation and its relation to outcome supports the suggestion that excision of the radial head is an essential part of an elbow synovectomy, by removing a mechanical block and allowing more complete synovectomy.

Age, gender, hand dominance, the presence of rheumatoid factor and duration of RA did not affect the outcome. We did not confirm the better outcome reported by Porter et al in males. ${ }^{2}$ The long duration of elbow symptoms predicted a poor outcome, possibly because of confounding with the preoperative range of flexion-extension.

Many studies have found no relation between the preoperative radiological stage and outcome. ${ }^{7,15,21}$ Most used the Steinbroker radiological grading. ${ }^{22}$ We used the more detailed Larsen scale ${ }^{11}$ and graded the humeroulnar and radiohumeral joints separately. We also looked for subluxation of the radial head and large cysts, but none of the radiological signs had any predictive value. Most studies on elbow synovectomy have shown that a grossly damaged elbow may still be compatible with a good outcome. ${ }^{3,4,6,15,17,21}$ All four of our patients in grade I were successes, but patients in this grade are only rarely operated on as they are more likely to respond to medical treatment. On the other hand, very few studies have suggested that elbows with radiologically advanced disease have a worse outcome. Porter et $\mathrm{al}^{2}$ alone have found a statistically significant relation in the subgroup of grade IV (Stein- 
brocker) when only those followed up for more than three years were included. ${ }^{2}$ With such subgrouping, a type-I statistical error becomes more likely. The trend towards better results in earlier disease shown by Ferlic et $\mathrm{al}^{16}$ has not been confirmed by larger studies.

Along with others, $2,7,16,17$ we found a significant incidence of recurrent synovitis, ulnar neuropathy and instability. These three clinical features significantly correlated with, and may have contributed to, failure. The relation of poor mobility to failure may be explained by the increased stress put on the rheumatoid elbow when the upper limbs are needed for transfer and mobility.

In RA the elbow is seldom involved in isolation. It is important to take account of the severity of disease in other joints of the upper limb. The three measures which we used to define function of the upper limb all correlated with outcome. The severity of RA in the ipsilateral shoulder also correlated with these three measures while that in the hand and wrist correlated only with the function of turning a door handle. These effects seem to be independent since there was no correlation between the outcome of synovectomy and the severity of RA in the other joints of the upper limb.

In rheumatoid arthritis, synovectomy and excision of the radial head should be recommended when it has a high chance of success, that is when forearm rotation is reduced to below $50 \%$ with no severe limitation of flexion-extension. A single favourable predictive factor may be accepted as an indication for operation in an unfit patient in whom a shorter operation is desirable and in young and more demanding patients with greater chance of long-term failure of total elbow replacement.

No benefits in any form have been received or will be received from a commercial party related directly or indirectly to the subject of this article.

\section{REFERENCES}

1. Amis AA, Dowson D, Wright V, Miller JH. The derivation of elbow joint forces, and their relation to prosthesis design. J Med Eng Technol 1979;3:229-34.

2. Porter BB, Richardson C, Vainio K. Rheumatoid arthritis of the elbow: the results of synovectomy. J Bone Joint Surg [Br] 1974;56-B: 427-37.

3. Wilson DW, Arden GP, Ansell BM. Synovectomy of the elbow in rheumatoid arthritis. J Bone Joint Surg [Br] 1973;55-B:106-11.

4. Taylor AR, Mukerjea SK, Rana NA. Excision of the head of the radius in rheumatoid arthritis. J Bone Joint Surg [Br] 1976;58-B: 485-7.

5. Vahvanen V, Eskola A, Peltonen J. Results of elbow synovectomy in rheumatoid arthritis. Arch Orthop Trauma Surg 1991;110:151-4.

6. Rymaszewski LA, Mackay I, Amis AA, Millar JH. Long-term effects of excision of the radial head in rheumatoid arthritis. $J$ Bone Joint Surg [Br] 1984;66-B:109-13.

7. Summers GD, Taylor AR, Webley M. Elbow synovectomy and excision of the radial head in rheumatoid arthritis: a short term palliative procedure. J Rheumatol 1988;15:566-9.

8. Souter WA. Surgery of the rheumatoid elbow. Ann Rheum Dis 1990; 49:871-82.

9. Arnett FC, Edworthy SM, Bloch DA, et al. The American Rheumatism Association 1987 revised criteria for the classification of rheumatoid arthritis. Arthritis Rheum 1988;31:315-24.

10. Amis AA, Miller JH. The elbow. Clin Rheum Dis 1982;8:571-93.

11. Larsen A, Dale K, Eek M. Radiographic evaluation of rheumatoid arthritis and related conditions by standard reference films. Acta Radiol [Diagn] (Stockh) 1977;18:481-91.
12. Daly LE, Bourke GJ, McGilvray J. Interpretation and uses of medical statistics. 4th edition. Oxford: Blackwell Scientific Publications, 1991:202-8.

13. Miettinen OS. Estimability and estimation in case-referent studies. Am J Epidemiol 1976;103:226-35.

14. Stein H, Dickson RA, Bentley G. Rheumatoid arthritis of the elbow: pattern of joint involvement, and results of synovectomy with excision of the radial head. Ann Rheum Dis 1975;34:403-8.

15. Tulp NJA, Winia WPCA. Synovectomy of the elbow in rheumatoid arthritis: long-term results. J Bone Joint Surg [Br] 1989;71-B:664-6.

16. Ferlic DC, Patchett CE, Clayton ML, Freeman AC. Elbow synovectomy in rheumatoid arthritis: long-term results. Clin Orthop 1987; 220:119-25.

17. Brumfield RH Jr, Resnick CT. Synovectomy of the elbow in rheumatoid arthritis. J Bone Joint Surg [Am] 1985;67-A:16-20.

18. Brattström H, Al Khudairy H. Synovectomy of the elbow in rheumatoid arthritis. Acta Orthop Scand 1975;46:744-50.

19. Copeland SA, Taylor JG. Synovectomy of the elbow in rheumatoid arthritis: the place of excision of the head of the radius. J Bone Joint Surg [Br] 1979;61-B:69-73.

20. Morrey BF, Askew LJ, An KN, Chao EY. A biomechanical study of normal functional elbow motion. J Bone Joint Surg [Am] 1981;63-A: 872-7.

21. Eichenblat M, Hass A, Kessler I. Synovectomy of the elbow in rheumatoid arthritis. J Bone Joint Surg [Am] 1982;64-A:1074-8.

22. Steinbrocker O, Traeger CH, Batterman RC. Therapeutic criteria in rheumatoid arthritis. JAMA 1949;140:659-62. 